\title{
Open Achilles tenotomy and posterior capsulotomy for congenital talipes equinovarus
}

\author{
Anil Agarwal ${ }^{1}$
}

Received: 20 April 2015 / Accepted: 22 June 2015 / Published online: 10 July 2015

(C) SICOT aisbl 2015

\section{Dear Editor,}

We read with interest the article by Grigoriou et al. [1]. The authors discussed clubfoot patients treated with serial Ponseti casting with equinus corrected either by percutaneous Achilles tenotomy (AT) or combined open Achilles tenotomy and posterior capsulotomy $(\mathrm{PC}+\mathrm{AT})$.

We would like to make some comments regarding the manuscript.

1. The protocol observed at authors' institution does not appear to conform to a standard Ponseti casting protocol [2]. The foot abduction criteria/talar head reduction prior to tenotomy procedure is not accounted. The equinus correction by $\mathrm{PC}+\mathrm{AT}$ at the surgeon's preference, even in a neonate, is probably also not aligned with the Ponseti method.

2. The $\mathrm{PC}+\mathrm{AT}$ procedure was chosen for those cases which had a higher degree of equinus (34.83) compared to PC (27.31). The authors also acknowledge these findings in discussion. Thus there seems a selection bias in cases with $\mathrm{PC}+\mathrm{AT}$; this procedure being reserved for more severe cases. It is further not clarified whether PC implies just opening of the ankle or the ankle with the subtalar joint, as both are closely related in a younger child with equinus. We would like to inquire from authors about the average age of performance of $\mathrm{PC}+\mathrm{AT}$, as in a neonate it is a technically demanding procedure.

3. World over, bracing and patient education are considered most important confounders for recurrence in clubfoot [2]. Although the authors describe these in limitations, the conclusions drawn regarding $\mathrm{AT}+\mathrm{PC}$ and $\mathrm{AT}$ alone in the study seems less justified in the absence of these.

\section{References}

1. Grigoriou E, Abol Oyoun N, Kushare I, Baldwin KD, Horn BD, Davidson RS (2015) Comparative results of percutaneous Achilles tenotomy to combined open Achilles tenotomy with posterior capsulotomy in the correction of equinus deformity in congenital talipes equinovarus. Int Orthop 39(4):721-725

2. Staheli L (ed) Clubfoot: Ponseti management, 3rd edn. Available from www.global-help.org
Anil Agarwal

rachna_anila@yahoo.co.in

1 Department of Paediatric Orthopaedics, Chacha Nehru Bal Chikitsalaya, Delhi, India 